\title{
The Study of Airflow Pattern Around a Maize Plant by Schlieren Optics
}

\author{
Wayne Y. Cheng ${ }^{1}$, Ping-chin Cheng ${ }^{2}$, David B. Walden ${ }^{3}$ \\ ${ }^{1}$ Williamsville East High School, East Amherst, NY 14051 USA \\ ${ }^{2}$ Dept. of Electrical Engineering, State University of New York at Buffalo, NY 14260 USA \\ ${ }^{3}$ Dept. of Plant Sciences, University of Western Ontario, London, Ontario, N6A5B7 Canada
}

Pollen dispersion in maize is highly depend on the airflow patter around the plant. At dehiscence, anther swings about the elongated filament and the pollens are shed through the now basally oriented pore. Pollens are shed from anthers due to the vibration caused by the air current. It is our interest to understand the air flow pattern around a maize plant, in particular the tassel. Schlieren optics is an ideal system to visualize the air flow pattern. The system reveals distortion of the wavefronts due to density gradients within the volume of interest [1]. In order to study the airflow pattern around a maize plant, a small wind tunnel was constructed (Fig. 3). Three 16-inch box fans were stacked in series to provide different airflow velocities. Laminar flow was achieved by using a honeycomb panel constructed by using $5 \mathrm{~mm}$ McDonald ${ }^{\mathrm{R}}$ plastic beverage straws (Fig. 4). A Kestrel 3000 anemometer (Nielsen-Kellerman, Chester, PA) was used to determine the air velocity. Two $15 \mathrm{~cm}$ spherical mirrors $(\mathrm{f}=150 \mathrm{~cm} 1 / 10 \lambda)$ were used to construct a Schlieren optical set-up (Figs. 1 and 3). A $100 \mathrm{~W} \mathrm{Hg}$ short arc lamp was used as the light source; a Sony ${ }^{\mathrm{TM}}$ camcorder operated in night-vision mode with built-in IR illuminator disabled was used to acquire the Schlieren images [2]. In addition, a second system using two f/3.5 Zeiss achormate lenses was constructed (Fig. 2), the system provides a beam diameter of $7 \mathrm{~cm}$ for higher resolution views. Acetone or Freon vapor was ejected from a set of specially made nozzles in the air stream (Fig. 4). The acetone/Freon vapor has a different reflective index from surrounding air, hence it can be easily delineated from the surrounding air. Plants were placed downstream from the nozzle in the wind tunnel, and rotated to allow a study of multiple wind directions.

At $3 \mathrm{~km} / \mathrm{h}$ and $4.6 \mathrm{~km} / \mathrm{h}$ breeze conditions, a significant updraft flow pattern and turbulence were detected when the lamellar airflow encountered leaf blades (Figure 5b, 5c, 5d, and 5e, arrows). The turbulence in the leeward side suggests significant drag acting on the plant. We have also observed an interesting turbulent pattern occurring at the tassel region of the plant (Figure 5f, $5 \mathrm{~g}$, arrows). This turbulence caused the tassel and the dehiscing anthers to vibrate even at low wind velocities and, in conjunction with the leaf-generated updraft, may play an important role in the efficient dispersing of pollen grains. The leaf-generated updraft may also minimize pollen deposition on the surface of the leaf. Downward draft can be observed only at the basal part of a leaf blade; this downward draft may assist the airborne pollen grains attaching to the silk. Due to the limitations on the size of the mirrors and the wind tunnel, our Schlieren optical study can only be preformed on young plants and isolated plant parts such as the tassel. Nevertheless, the results demonstrate the potential application of Schlieren optics to the study of aerodynamic response and pollen dispersion of maize.

This article is part of a report by WYC for Siemens Westinghouse Science and Technology Competition (2000, Semi Finalist) and Intel Science Talent Search (2001, Semi Finalist).

[1] J. R. Strickler and J. S. Hwang: In: Focus on Multidimensional Microscopy, vol. 2, eds. P. C. Cheng et al., World Scientific Publishing (1999) 217-239.

[2] W. Y. Cheng et al., Maize Genetic Cooperation Newsletter., vol. 76, (2002, in press) 
1

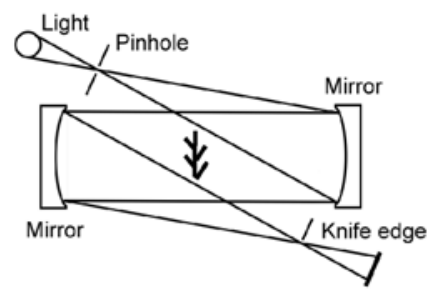

2

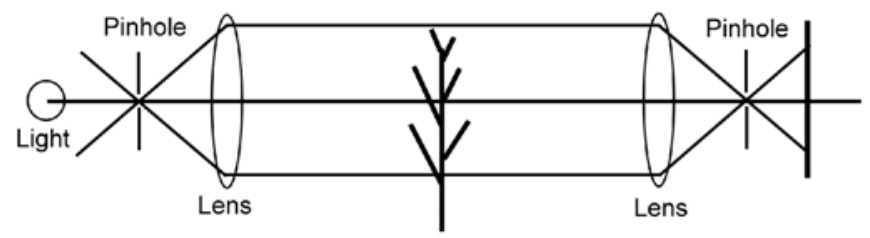

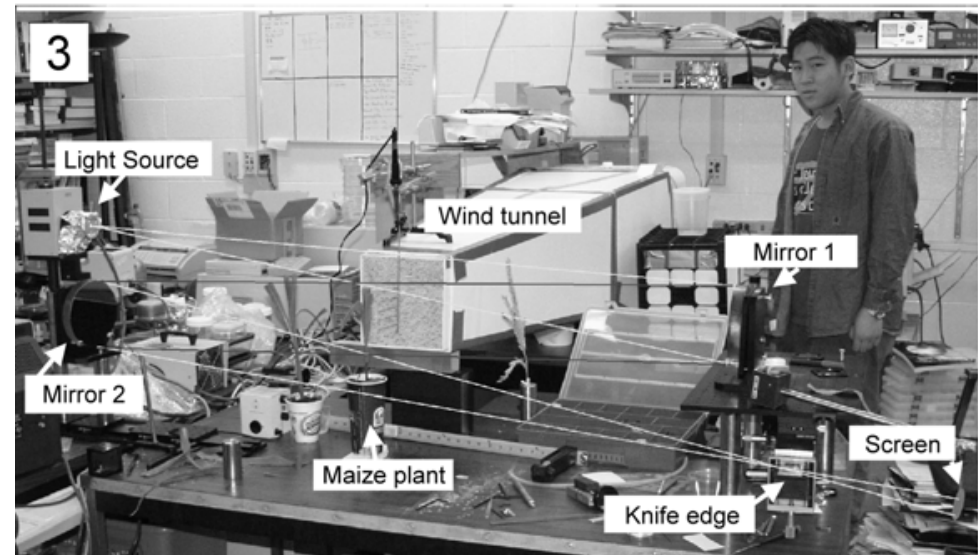
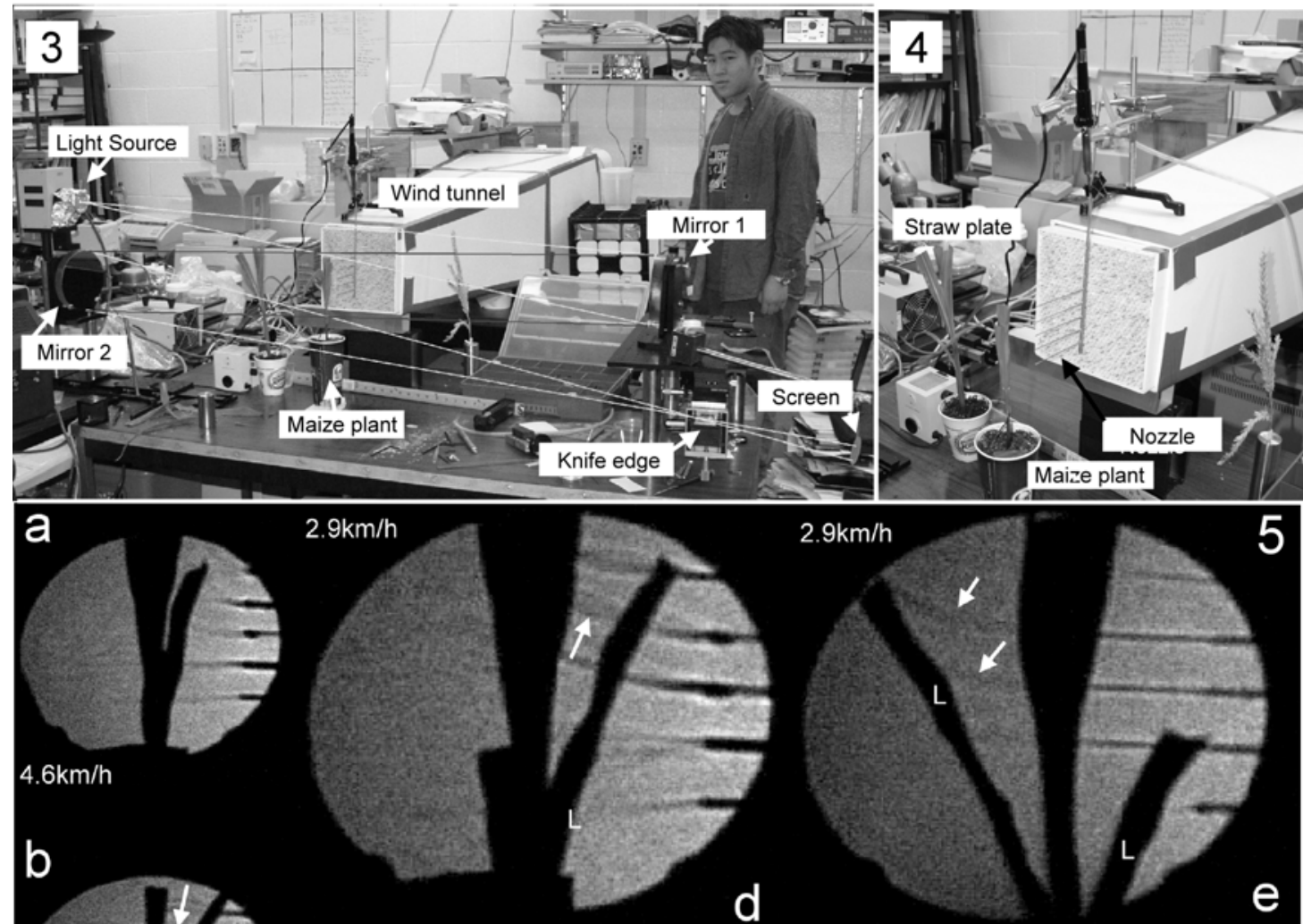

$2.9 \mathrm{~km} / \mathrm{h}$
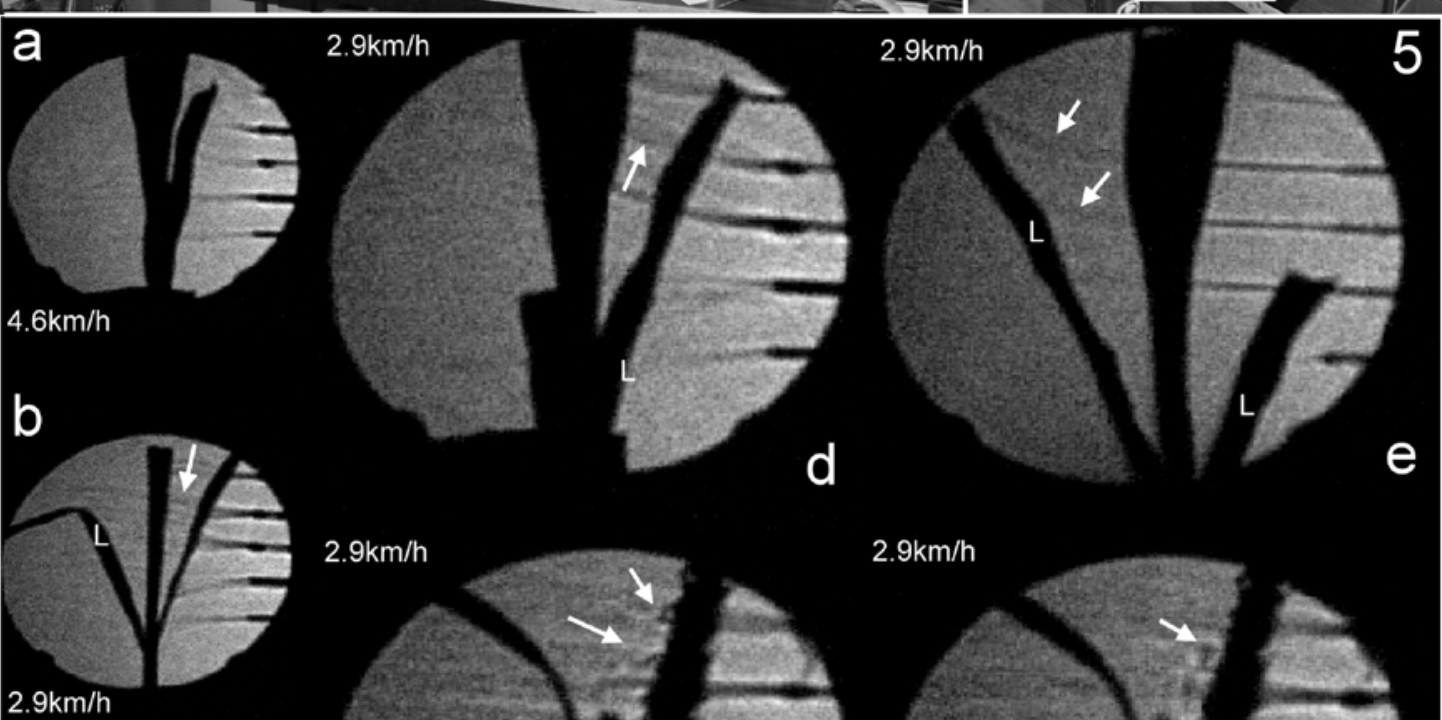

d

e

$2.9 \mathrm{~km} / \mathrm{h}$

C

$2.9 \mathrm{~km} / \mathrm{h}$
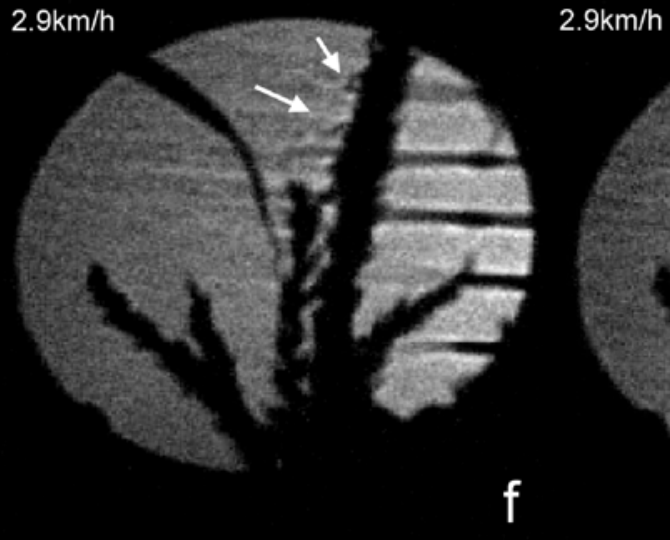

$2.9 \mathrm{~km} / \mathrm{h}$

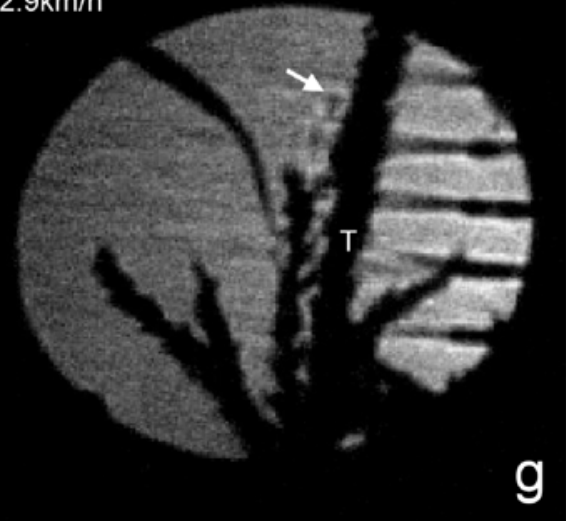

FIG 1 and 2: Schlieren optics layout using mirrors and lenses.

FIG. 3 and 4: Schlieren optical setup with wind tunnel. Straw plate and nozzle are evident in Fig. 4. FIG 5: (a-g), Airflow pattern around a plant, L: leaf, T: tassel, white arrows: turbulence flow. 